\title{
Eficiencia de solubilización de fósforo de aislados nativos guatemaltecos de Pseudomonas fluorescens
}

\author{
Phosphorus solubilization efficiency of native Guatemalan isolates \\ of Pseudomonas fluorescens
José A. Ruiz-Chután (DD 1,2*, Julio E. Berdúo-Sandoval (D) 1, Aníbal Sacbajá1, Marie Kalousová (D) 2 Bohdan Lojka (D) ${ }^{2}$, Eloy Fernández (D) ${ }^{2}$, Jana Žiarovská (iD ${ }^{3}$, Amílcar Sánchez-Pérez ${ }^{1}$
${ }^{1}$ Facultad de Agronomía, Universidad de San Carlos de Guatemala, Guatemala ${ }^{2}$ Department of Crop Sciences and Agroforestry, Czech University of Life Sciences Prague, Czech Republic ${ }^{3}$ Department of Genetics and Plant Breeding, Slovak University of Agriculture in Nitra, Slovak Republic \\ *Autor al que se dirige la correspondencia: josealejandro.ruiz@icloud.com
}

\section{Resumen}

Recibido: 30 de mayo 2020 / Revisión: 29 de enero 2021 / Aceptado: 28 de octubre 2021

E 1 fósforo (P) es un elemento esencial en la producción agrícola, pero debido a su compleja dinámica en el - suelo, solo una pequeña cantidad es aprovechable para las plantas, ya que la mayoría del P se encuentra en formas insolubles, especialmente, en suelos Andisoles de origen volcánico. Los microorganismos con capacidad solubilizadora de fósforo (MSF) son una alternativa para transformar el $\mathrm{P}$ a formas solubles y aprovechables por las plantas; además de brindar múltiples beneficios ambientales. Este trabajo identificó y evaluó in vitro, aislados nativos de Pseudomonas fluorescens Mingula, obtenidos de regiones guatemaltecas con suelos Andisoles que limitan la producción agrícola por la alta fijación de P. Se realizaron cultivos in vitro de la bacteria en medio National Botanical Research Instituteís phosphate growth (NBRIP), con fosfato tricálcico $\mathrm{Ca}_{3}\left(\mathrm{PO}_{4}\right)_{2}$ como fuente de P insoluble y se midió el índice de solubilización de fósforo (ISF). Un total de 35 aislados de P. fluorescens fueron identificados y confirmados por PCR específico. El análisis de relaciones genéticas con el marcador AFLP, mostró dos grupos: el grupo A incluyó a los aislados con ISF mayores a 1.75, mientras el grupo B incluyó a aquellos con ISF menor a 1.75. La comparación de ISF entre los aislados y departamentos, demostró diferencia estadísticamente significativa $(p<.001)$, con el aislado Pf_33 como más eficiente. Debido al potencial de solubilización de los aislados nativos del grupo genético A (ISF $>1.75$ ), estos se recomiendan para futuras investigaciones que determinen su respuesta a condiciones de campo y estrategias para el desarrollo de biofertilizantes.

Palabras claves: disponibilidad de fósforo, Andisoles, relaciones genéticas, índice de solubilización, estabilidad de solubilización

Abstract

$\mathrm{P}$ hosphorus (P) is an essential element in agricultural production, but due to its complex dynamics in the soil, only a tiny amount is usable by plants. This is because most $\mathrm{P}$ is in insoluble forms, especially in volcanic Andisol soils. Microorganisms with phosphorus solubilizing capacity (MSF) are an alternative for transforming $\mathrm{P}$ into soluble forms usable by plants and providing multiple environmental benefits. This research identified and evaluated in vitro native isolates of Pseudomonas fluorescens Mingula, obtained from Guatemalan regions with Andisol soils that limit agricultural production due to high $P$ fixation. In vitro cultures of the bacteria were grown on the National Botanical Research Instituteís phosphate medium (NBRIP), with tricalcium phosphate $\mathrm{Ca}_{3}\left(\mathrm{PO}_{4}\right)_{2}$ as a source of insoluble $\mathrm{P}$, and We measured the phosphorus solubilization index (PSI). We identified and confirmed a total of 35 isolates of $P$. fluorescens by specific PCR. Using the AFLP marker, genetic relationship analysis showed two groups: group A included isolates with PSI greater than 1.75, while group B included those with FSI less than 1.75. Comparing of PSI between isolates and departments showed statistically significant differences $(p<0.001)$, respectively, with the Pf_33 isolate as the most efficient. Because of the high solubilization potential of the native isolates of genetic group A (FSI > 1.75), We recommend future research to determine their response to field conditions and strategies for biofertilizer development.

Keywords: Phosphorus solubilization, Andisols, genetic diversity, solubilization index, solubilization stability 


\section{Introducción}

El fósforo $(\mathrm{P})$ es el segundo nutriente más abundante en el suelo después del nitrógeno (Hariprasad \& Niranjana, 2009). Este es esencial para el desarrollo y crecimiento de las plantas y representa hasta el $0.2 \%$ del peso seco de estas (Azziz et al., 2012; Tak et al., 2012). La deficiencia de P produce plantas atrofiadas con una coloración púrpura en las hojas, además de provocar una baja eficiencia fotosintética y retrasar los procesos de maduración (Kruse et al., 2015; Sharma, 2011). Junto al nitrógeno (N), el P se considera como nutriente limitante en la producción agrícola en regiones subtropicales (Kuhad et al., 2011) como Guatemala.

En cuanto al origen del P, este tiene lugar a partir de las apatitas y depósitos de fosfato natural de donde se obtiene mediante los procesos de meteorización, lixiviación, erosión y extracción industrial como fertilizante (Cerón \& Aristizábal, 2012; Shen et al., 2011). El P presenta un ciclo dinámico y complejo en el suelo que involucra procesos como la adsorción/desorción, precipitación/disolución, mineralización/inmovilización, meteorización y transformaciones de $\mathrm{P}$ en la fase sólida, como la difusión, penetración y recristalización en la fase sólida (Hou et al., 2019). Este dinamismo provoca que solo una pequeña porción del fósforo soluble en el suelo pueda ser aprovechado por las plantas, mientras que el resto del $\mathrm{P}$ queda en formas insolubles o fijadas en la superficie de las arcillas coloidales (Espinosa-Sánchez \& Sanabria, 2015; Melenya et al., 2015).

El fenómeno de fijación de P se presenta fuertemente en suelos originados a partir de cenizas volcánicas, principalmente los Andisoles, lo que restringe la cantidad de P disponible para las plantas (Borie $\&$ Rubio, 2003). Por esta razón, los Andisoles tienen un alto requerimiento de aplicación de fertilizantes como fuente de P para cumplir con los requerimientos nutricionales de las plantas (Dahlgren et al., 2004). Anualmente, se estima que en todo el mundo se aplican alrededor de 52.3 billones de toneladas de fertilizantes fosfatados (Organización de las Naciones Unidas para la Agricultura y la Alimentación, 2019) de los cuales alrededor de $0.2 \%$ es aprovechado por las plantas (Islam et al., 2019). El resto del P es fijado o retenido en formas insolubles para las plantas al formar fosfatos con aluminio $\left(\mathrm{AlPO}_{4}\right)$ o hierro $\left(\mathrm{FePO}_{4}\right)$ en suelos ácidos y con calcio $\left(\mathrm{Ca}_{3} \mathrm{PO}_{4}\right)$ en suelos alcalinos o calcáreos (Callejas-Cañarte et al., 2018; Delfim et al., 2018). Esto se traduce en altas concentraciones de $\mathrm{P}$ en la mayoría de agroecosistemas desarrollados en Andisoles, del cual solo una pequeña porción está disponible y puede ser aprovechado por las plantas (Redel et al., 2007; Velásquez et al., 2016).

Actualmente, las cuantificaciones de las reservas de $\mathrm{P}$ sugieren que estas podrían agotarse en un período de 50 a 100 años, ya que para el 2030 se pronostica que la demanda de fósforo llegue a su punto máximo (Cordell et al., 2009). Dado el incremento en la demanda de la producción agrícola, la disponibilidad de $P$ es de vital importancia para garantizar la seguridad alimentaria (Cordell et al., 2011; Kamal et al., 2019)

El mal manejo de los fertilizantes tiene un alto impacto ambiental debido a las pérdidas por lixiviación, escorrentía de nutrientes (Delfim et al., 2018; Liu et al., 2018), acumulación de metales pesados, entre otros (AlKhader, 2015). Se ha reportado que la escorrentía de $\mathrm{P}$ y $\mathrm{N}$ ha acelerado el proceso de eutrofización y brote de algas que ponen en riesgo los ecosistemas acuáticos (Chowdhury et al., 2017) tal es el caso del Lago de Atitlán (Rejmánková et al., 2011) y el Lago de Izabal (Obrist-Farner et al., 2019) en Guatemala. Además de los impactos ya mencionados, la producción de fertilizantes fosfatados también es costosa e insostenible (Situmorang et al., 2015).

Ante este escenario, el uso de microorganismos solubilizadores de fósforo (MSF) surge como una alternativa prometedora para tener una producción agrícola con bajo impacto ambiental (Alori et al., 2017). Estos microorganismos incrementan la disponibilidad de fósforo, por lo que se consideran una opción prometedora a la dependencia de fertilizantes de síntesis química. Los MSF han sido aislados de diversos suelos y cultivos existiendo numerosos reportes de su éxito al ser evaluados en diferentes condiciones de campo e in vitro (Chawngthu et al., 2020; Hii et al., 2020; Linu et al., 2019; Munir et al., 2019). Estos antecedentes sustentan la importancia de la investigación de los MSF en Guatemala para lograr su futura aplicación en la producción agrícola.

Entre los MSF, destacan las bacterias solubilizadoras de fósforo (BSF) por su alta capacidad de solubilización, que incrementan la disponibilidad de $\mathrm{P}$ a través de la producción y liberación de distintos ácidos orgánicos en el suelo (Billah et al., 2019; Liang et al., 2020) por lo cual son una opción prometedora para ser utilizados como biofertilizantes (Batool \& Iqbal, 2019; Kalayu, 2019). Dentro de las BSF, la especie Pseudomonas fluorescens es particularmente conocida por sus múltiples funciones como biocontrol 
(Pérez-Álvarez et al., 2015), estimulante de crecimiento en plantas (Elekhtyar, 2016; Qessaoui et al., 2019) y, sobre todo, por su capacidad de biofertilización por su acción solubilizadora de P (Breitkreuz et al., 2020; Rahman et al., 2017; Sarikhani et al., 2020; Yadav et al., 2016).

En Guatemala se reportan agroecosistemas, como el Valle de Almolonga, Quetzaltenango, con valores que sobrepasan los rangos óptimos (12-16 ppm) de P (Pérez-Reynoso, 2008). Esto es consecuencia del uso desmedido de fertilizantes fosfatados. A la fecha no existen publicaciones sobre la evaluación de microorganismos solubilizadores de fósforo en el país. Como respuesta a la problemática de la fijación de fósforo y ante la falta de estrategias sostenibles a dicha situación a nivel nacional, esta investigación tuvo como objetivo evaluar la eficiencia de solubilización, bajo condiciones in vitro, de aislados nativos de $P$. fluorescens obtenidos de suelos Andisoles de Guatemala y vincular sus relaciones genéticas con la eficiencia solubilizadora.

\section{Materiales y Métodos}

\section{Muestreo y aislamientos de $\boldsymbol{P}$. fluorescens}

Durante los meses de abril a agosto del año 2019, un total de 40 muestras de suelo fueron colectadas en los departamentos de Sacatepéquez, Chimaltenango, Escuintla, Sololá, Totonicapán, Quetzaltenango y San Marcos; por su ubicación en la región de suelos Andisoles (Figura 1). Cada muestra consistió en $1 \mathrm{Kg}$ de suelo, el cual fue tomado a una profundidad de 10-15 $\mathrm{cm}$ en el área de la rizófera de cultivos ubicados en las áreas de muestreo. También se tomaron muestras en zonas boscosas sin presencia de cultivos (Figura 2). El suelo colectado fue depositado en bolsas plásticas estériles y transportado al laboratorio de Biotecnología de la Facultad de Agronomía, USAC y posteriormente tamizado a $2 \mathrm{~mm}$ (McPherson et al., 2018).

Figura 1

Mapa de ubicación de las muestras de suelo colectas en la región de suelos Andisoles de Guatemala

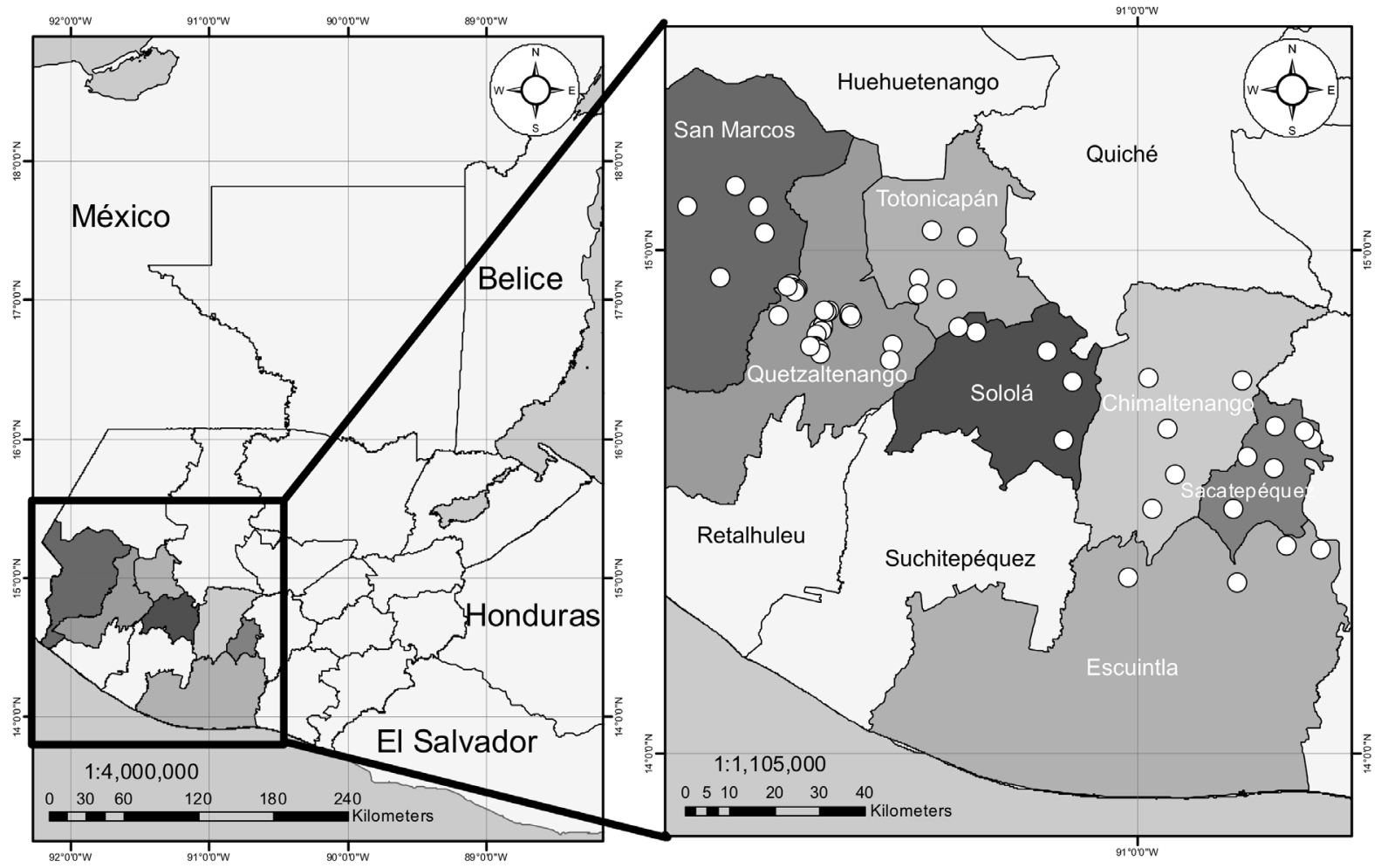


El proceso de aislamiento de las bacterias fue realizado mediante el método de diluciones seriadas, para lo cual se tomó $1 \mathrm{~g}$ de suelo y se diluyó en $9 \mathrm{~mL}$ de agua desmineralizada estéril, obteniendo una dilución $10^{-1}$, a partir de esta se realizaron diluciones hasta $10^{-4}$. De la dilución $10^{-4}$ se tomaron $20 \mu$ que fueron inoculados sobre el medio de cultivo King B reportado por King y colaboradores (1954) como medio diferencial para P. fluorescens. Las cajas de Petri fueron selladas con papel Parafilm y se incubaron a $28{ }^{\circ} \mathrm{C}$ en oscuridad, observándolas a los 3 días para identificar el desarrollo de colonias bacterianas y exponiéndolas a luz UV para la identificación de las colonias fluorescentes (Johnsen \& Nielsen, 1999).

\section{Extracción de ADN}

Para la extracción del ADN se empleó el kit comercial Gentra ${ }^{\circledR}$ basado en la metodología propuesta por el fabricante para bacterias Gram negativas.

\section{Identificación molecular de P. fluorescens}

Para la identificación molecular se realizó una PCR con los cebadores 16SPSEfluF (5'- TGCATTCAAAACTGACTG - 3') y 16SPSER (5'- AATCA-
CACCGTGGTAACCG - 3') (Scarpellini et al., 2004). La reacción fue preparada para un volumen de $50 \mu \mathrm{L}$ conteniendo solución de amortiguación para PCR (1X), DNTP's (200 $\mu \mathrm{M}$ de cada uno), $\mathrm{MgCl} 2$ (2mM), cebador ( $0.5 \mu \mathrm{M}$ de cada uno), TaqDNA polimerasa ( 1 unidad) y ADN (50ng). Las condiciones para la PCR fueron las siguientes: Un ciclo a $941 / 4 \mathrm{C}$ por $5 \mathrm{~min}$, seguido de 30 ciclos a $94{ }^{\circ} \mathrm{C}$ por $1 \mathrm{~min}, 55^{\circ} \mathrm{C}$ por $1 \mathrm{~min}, 72{ }^{\circ} \mathrm{C}$ por 2 min y una extensión final de $72^{\circ} \mathrm{C}$ por $10 \mathrm{~min}$. Las reacciones positivas generaron un fragmento de $850 \mathrm{pb}$. Las muestras se amplificaron en un termociclador Bio Rad PTC-200. Todos los productos de PCR generados fueron separados por electroforesis en gel de agarosa al $1.5 \%$ teñidos con bromuro de etidio $(0.1 \mu \mathrm{g} / \mathrm{mL})$ en amortiguador TAE $1 \mathrm{X}$ y visualizados en un transiluminador de luz UV. Para la determinación del tamaño de los fragmentos obtenidos se utilizó un marcador de peso molecular $3 \mathrm{~Kb}$ (SibEnzyme Ltd.).

\section{Protocolo de AFLP para la caracterización molecular de $P$. fluorescens}

El marcador molecular AFLP (Vos et al., 1995) fue utilizado debido a su alta capacidad para identificar regiones polimórficas en el genotipado de varias especies del género Pseudomonas (Abdul-Wahab et al.,

\section{Figura 2}

Detalle del sitio de colecta, cultivo de donde se tomaron las muestras de suelo para el aislamiento de Pseudomonas fluorescens y resultados de la confirmación de la especie por PCR

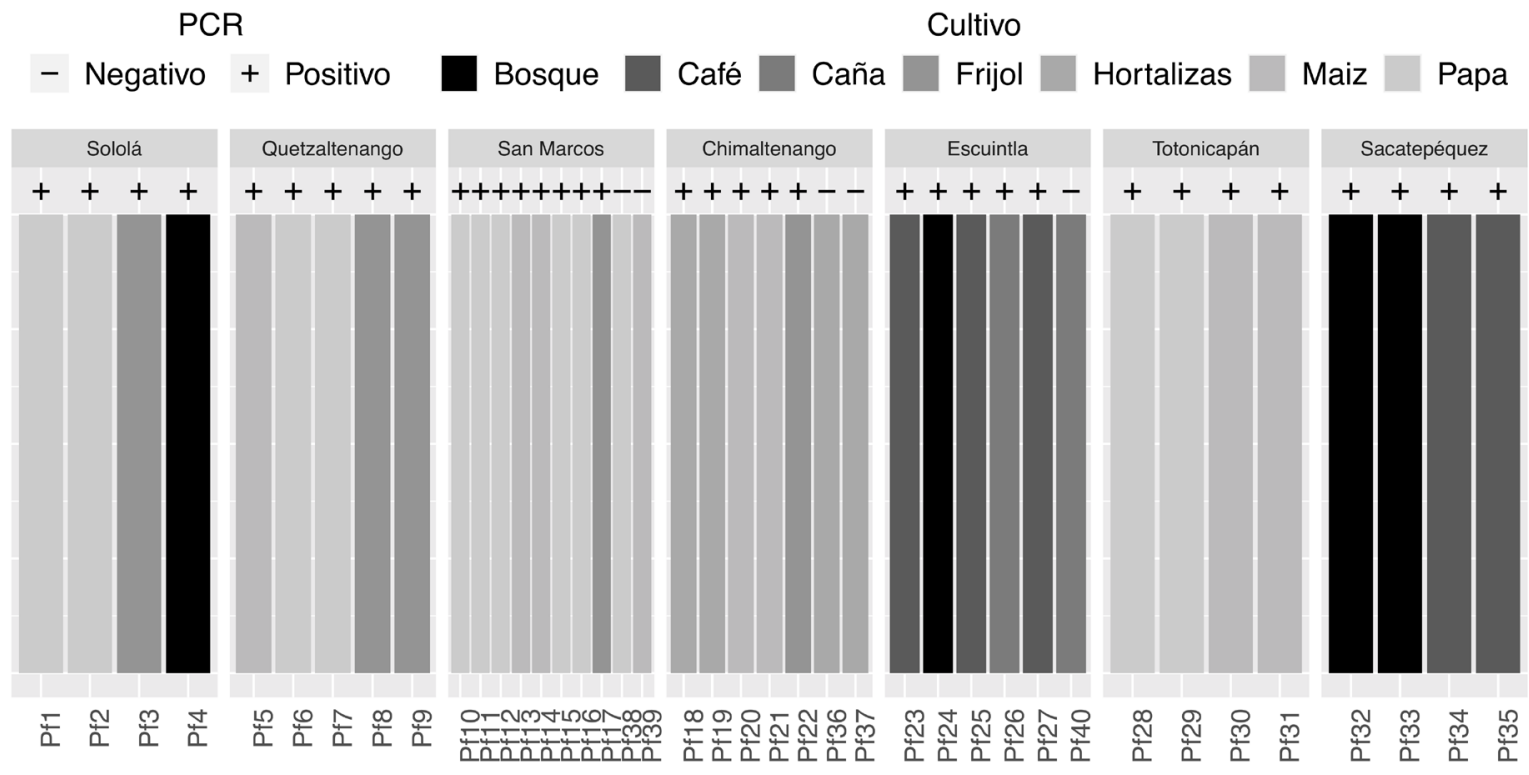


2014; Kumar et al., 2014). A partir de las muestras positivas mediante PCR, se desarrolló la siguiente metodología: se utilizó ADN genómico a una concentración de $10 \mathrm{ng} / \mu \mathrm{L}$, el cual fue digerido con las enzimas de restricción EcoR1/ Mse1 y se incubó por $2 \mathrm{~h}$ a $37^{\circ} \mathrm{C}$ y después a $70^{\circ} \mathrm{C}$ por $15 \mathrm{~min}$ para desactivar las enzimas de restricción. La ligación de los adaptadores se llevó a cabo con los reactivos del kit AFLP ${ }^{\circledR}$ Analysis Sistem for Microorganism y se incubó durante $2 \mathrm{~h}$ a $20^{\circ} \mathrm{C}$. Seguidamente se realizó una preamplificación con la reacción en cadena de la polimerasa; el programa empleado en el termociclador fue el siguiente: $94{ }^{\circ} \mathrm{C}$ por $30 \mathrm{~s}, 56{ }^{\circ} \mathrm{C}$ por $60 \mathrm{~s}, 72{ }^{\circ} \mathrm{C}$ por $60 \mathrm{~s}$, por 20 ciclos. Los productos amplificados se visualizaron en un gel de agarosa al 2\%. Se hizo una amplificación selectiva con los cebadores M-A + E-C del kit los cuales produjeron mayor polimorfismo.

Los productos de la PCR se visualizaron en un gel de acrilamida al 5\% para poder observar las bandas amplificadas. La tinción del gel se realizó con nitrato de plata mediante el siguiente procedimiento: inmersión en solución fijadora de ácido acético glacial 10\% $\mathrm{v} / \mathrm{v}$ durante $35 \mathrm{~min}$, agua destilada durante $20 \mathrm{~min}$, solución de tinción (nitrato de plata $0.15 \% \mathrm{p} / \mathrm{v}$, formaldehído $0.15 \% \mathrm{v} / \mathrm{v}$ ) por $40 \mathrm{~min}$, agua destilada por $10 \mathrm{~s}$, solución de revelado de 5 a 6 min según la aparición de las bandas (carbonato de sodio $6 \% \mathrm{p} / \mathrm{v}$, formaldehído $0.3 \% \mathrm{v} / \mathrm{v}$, tiosulfato de sodio $5 \mathrm{ppm}$ ), solución fijadora para detener el proceso durante aproximadamente 5 min, finalmente se lavó en agua destilada. Se dejó secar por 2 días y posteriormente se realizó la lectura del perfil de las bandas (Karam et al., 2006).

\section{Evaluación cualitativa de la eficiencia y estabilidad de solubilización de $\boldsymbol{P}$. fluorescens bajo condiciones in vitro}

Con los aislados obtenidos en medio de cultivo diferencial y posteriormente confirmados por PCR, se realizó la evaluación de solubilización con el medio de cultivo Nacional Botanical Research Instituteis Phosphate growth medium (NBRIP, en g/L: Glucosa, $10 ;\left(\mathrm{NH}_{4}\right)_{2} \mathrm{SO}_{4}, 0.1 ; \mathrm{KCl}, 0.2 ; \mathrm{MgSO}_{4} .7 \mathrm{H}_{2} \mathrm{O}, 0.25 ; \mathrm{Mg}-$ $\mathrm{Cl}_{2} .6 \mathrm{H}_{2} \mathrm{O}$, 5; Agar, 14; pH 7; $\left.\mathrm{Ca}_{3}\left(\mathrm{PO}_{4}\right)_{2}, 5\right)$ (Nautiyal, 1999). Se añadió azul de bromofenol $(0.025 \mathrm{~g} / \mathrm{L})$ como indicador de cambio de $\mathrm{pH}$ para identificar la producción de ácidos orgánicos debido al cambio de coloración de azul a amarillo. A partir de cada aislado confirmado por PCR, se prepararon soluciones a una concentración de $10^{6} \mathrm{UFC} / \mathrm{mL}$, de los cuales se tomaron $20 \mu \mathrm{L}$ para realizar la inoculación en el medio
NBRIP en cajas de Petri. Las cajas fueron selladas con papel Parafilm e incubadas a $28^{\circ} \mathrm{C}$ durante 15 días (Nautiyal, 1999).

Durante dicho período se realizaron lecturas a los 7 y 15 días para tomar datos del diámetro del halo de solubilización y diámetro de crecimiento de la colonia. A partir de estos datos se calculó el índice ISF, el cual es una relación entre el diámetro del halo de solublización y diámetro de crecimiento de la colonia (Kumar \& Narula, 1999). Cada uno de los 35 aislados fue replicado 3 veces en un diseño completamente al azar (DCA). Para verificar la estabilidad de solubilización, cada uno de los aislados se sometió a 5 resiembras consecutivas en medio NBRIP con un espaciamiento de 2 semanas entre cada resiembra y se realizó el cálculo de ISF a los 15 días.

\section{Análisis de datos}

Con el perfil de bandas obtenido del gel de poliacrilamida, se generó una matriz binaria de presencia (1) ausencia (0) para cada uno de los loci amplificados. La matriz se exportó al programa Paleontological Statistics Software Package for Education and Data Analysis Past v3.18 (Ryan et al., 2001) para generar una matriz de distancias genéticas con el índice de Dice y posterior agrupamiento con el método Neighbor-Joining (NJ) (Saitou \& Nei, 1987) para generar un dendrograma en formato Nexus, el cual fue exportado hacia la herramienta en línea iTOL v4 (Letunic \& Bork, 2019) para una mejor visualización del dendrograma.

Con los datos obtenidos de la evaluación de la eficiencia de solubilización de fósforo, a través del ISF, se realizaron las pruebas de Shapiro y Bartlett para determinar la normalidad de los residuos y homogeneidad de varianzas, respectivamente, obteniéndose valores de $p<.05$ para ambas pruebas. Posteriormente, se realizó un análisis de varianza a través de la prueba no paramétrica de Kruskal-Wallis con un nivel de significancia del 5\% y el cálculo del tamaño del efecto de los factores evaluados mediante epsilon cuadrado $\epsilon^{2}$. A continuación se realizaron comparaciones de medias por pares con la prueba de Dunn y 5\% de significancia con la corrección de Bonferroni. Las pruebas anteriormente descritas se realizaron en el programa $\mathrm{R} v$ v.0.3 con los paquetes stats (R core Team, 2020) y agricolae v 1.4.0 (de Mendiburu \& Yessen, 2020). La visualización de los resultados de las pruebas de t de Student, análisis de varianza y comparaciones pareadas, se realizaron con el paquete ggstatsplot v 0.9.0 (Patil, 2021). 


\section{Resultados}

A partir de las muestras colectadas, se obtuvo un total de 40 aislados en el medio de cultivo diferencial identificados por su fluorescencia al ser expuestos a luz UV-A. Tras la prueba de PCR, se identificaron 35 aislados positivos (banda de $850 \mathrm{pb}$ ) y 5 aislados negativos para la presencia de $P$. fluorescens (Figura 2 y 3). A partir del análisis de relaciones genéticas se identificaron 2 grupos principales en el dendrograma.

El grupo A reunió un total de quince aislados, los cuales procedían, mayormente, del departamento de Escuintla (4), la región central con el departamento de Sacatepéquez (3) y el altiplano central con el departamento de Chimaltenango (4) observándose una relación positiva entre la distancia geográfica y genética. En este grupo también se ubicaron pocos aislados (4) geográficamente más distantes, procedentes de Sololá (2), Quetzaltenango (1) y San Marcos (1) (Figura 4). Todos los aislados en este grupo mostraron una alta capacidad de solubilización en base a la prueba de eficiencia que se detallan en la Figura 6.

El grupo B reunió un total de veinte aislados, los cuales procedían en su mayoría de la región del altiplano occidental del departamento de Sololá (2), Totonicapán (4), Quetzaltenango (cuatro) y San Mar- cos (siete) manteniendo una relación positiva entre la distancia geográfica y genética. En este grupo también se ubicaron cinco aislados geográficamente más distantes procedentes de Sacatepéquez (uno), Escuintla (uno) y Chimaltenango (uno). Todos los aislados en este grupo fueron clasificados como capacidad variable (media-baja) de solubilización.

Tras realizar el análisis de varianza con los valores de ISF, se identificó una diferencia estadísticamente significativa en la actividad solubilizadora entre los aislados evaluados con un $p<.001$ y un tamaño del efecto debido a los aislados catalogado como grande $\left(\epsilon^{2}=.94\right)$. Tras realizar la comparación de medias por pares, mediante la prueba de Dunn, el aislado Pf_33, proveniente de Sacatepéquez, se ubicó como el más eficiente. Seguido el Pf_24 y Pf_33 provenientes de Escuintla y Sacatepéquez como el segundo y tercer aislados más eficientes, respectivamente. El comportamiento de los valores de ISF de cada aislado se detalla en la Figura 6. Los tres aislados mencionados fueron colectados de la rizósfera de árboles en zonas boscosas (Figura 2)

Al realizar el análisis de varianza para comparar la capacidad solubilizadora a partir de su sitio de colecta, también existió diferencia estadísticamente significativa con un $p<.001$ con un tamaño del efec-

Figura 3

Productos amplificados por PCR con los cebadores P16SPSEfluF/16SPSER para la identificación de Pseudomonas fluorescens

\section{$\begin{array}{llllllllllll}\text { Pf30 } & \text { Pf31 } & \text { Pf32 } & \text { Pf33 } & \text { Pf34 } & \text { Pf35 } & \text { Pf36 } & \text { Pf37 } & \text { Pf38 } & \text { CP } & \text { CN } & \text { MP }\end{array}$}

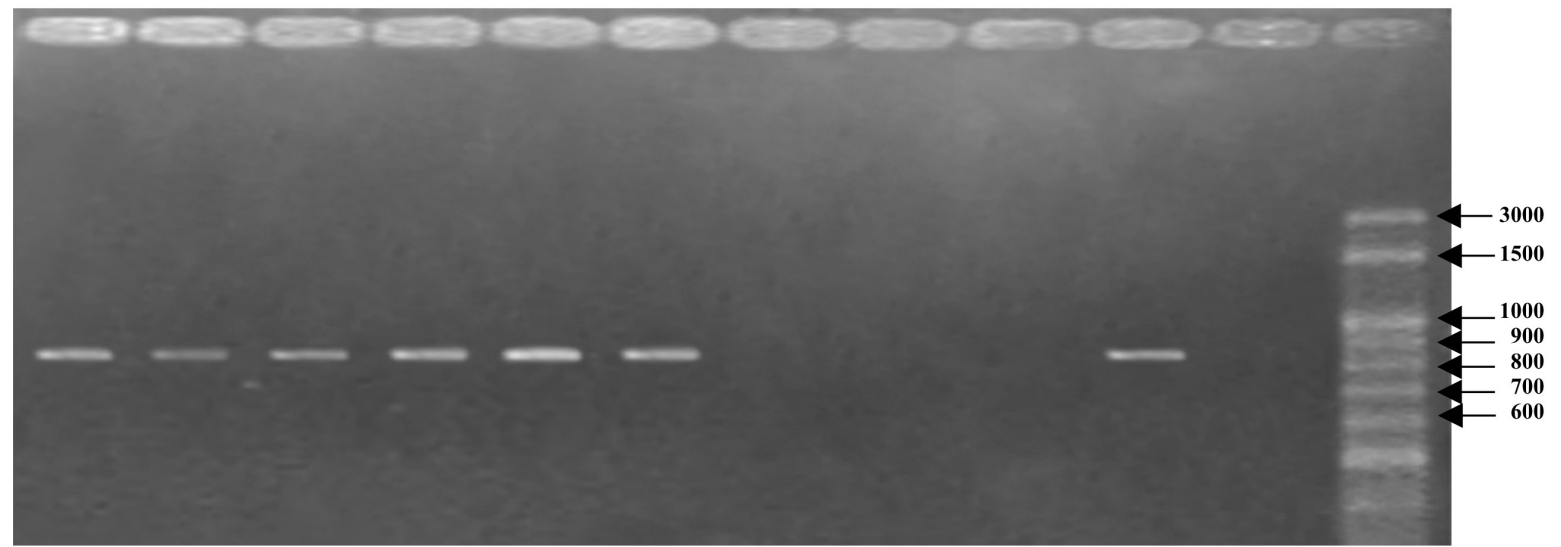

Nota. Carrilles $1-6$ muestras del aislado Pf_30 al Pf_35 respectivamente. Carriles $7-9$ muestras del aislado Pf_36 al Pf 38. $\mathrm{CP}=$ control positivo. $\mathrm{CN}=$ control negativo (agua estéril). $\mathrm{MP}=$ marcador de peso molecular DNA Ladder $3 \mathrm{~Kb}$ (SibEnzyme Ltd. $\left.{ }^{\circledR}\right)$. 
Figura 4

Dendrograma tipo Neighbor-Joining (NJ) generado a partir de 35 aislados de Pseudomonas fluorescens genotipados con el marcador molecular amplified fragment length polymorphism (AFLP) que muestra la relación genética de los aislados y el vínculo con su capacidad solubilizadora de P. La capacidad de solubilización de cada grupo de aislados se indica en los recuadros

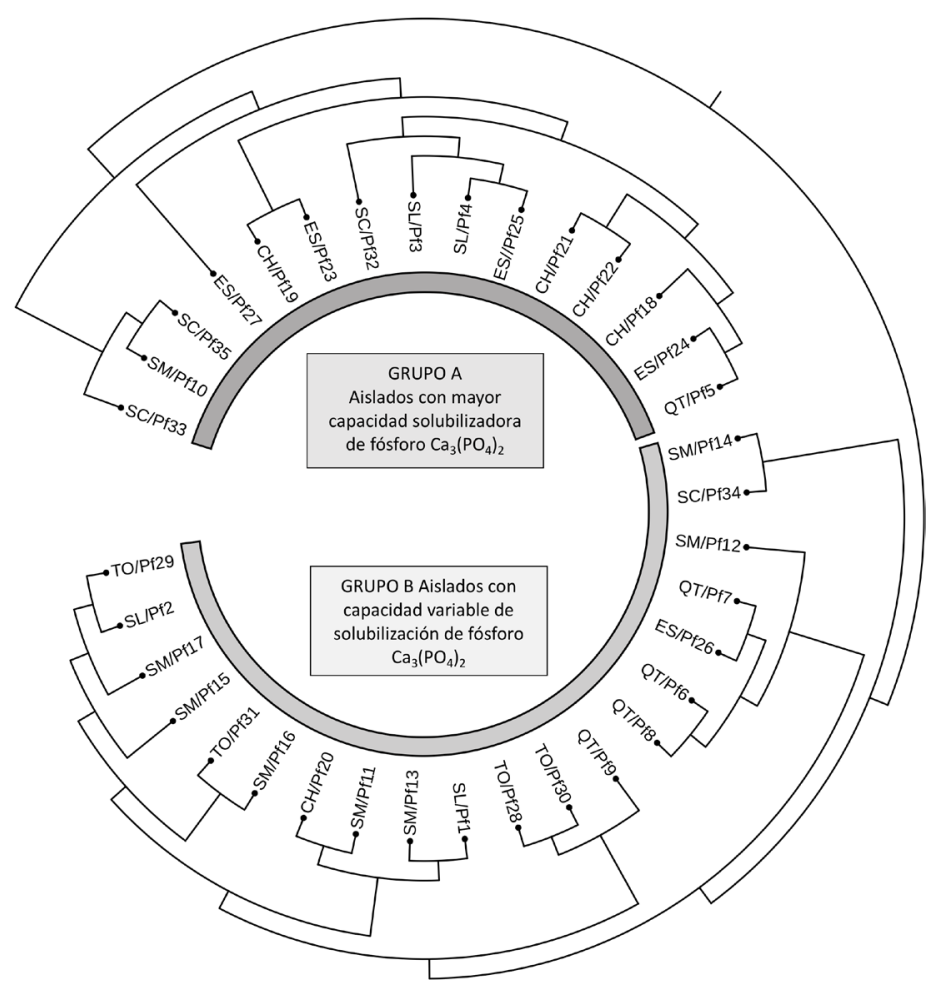

Nota. Al nombre de cada aislado se antepuso el sitio de colecta para facilitar su ubicación geográfica, Toto $=$ Totonicapán, Quet $=$ Quetzaltenango, Chimal $=$ Chimaltenango, SnMc $=$ San Marcos, Esc $=$ Escuintla, Sac $=$ Sacatepéquez, Sol = Sololá

to debido al sitio de colecta catalogado como medio $\left(\epsilon^{2}=.32\right)$. Tras realizar la comparación de medias por pares, mediante la prueba de Dunn, el departamento con mayor valor de índice de solubilización fue Sacatepéquez, seguido de Escuintla y Chimaltenango. Posteriormente, se ubicaron los departamentos de Sololá, Quetzaltenago, San Marcos, mientras que el valor medio más bajo se obtuvo en el departamento de Totonicapán. El detalle del comportamiento de los valores de ISF por departamento se muestra en la Figura 7.

Al evaluar la estabilidad de solubilización, se observó que el comportamiento es variado entre todos los aislados. No se observó ningún departamento en el cual todos los aislados incrementaran, mantuvieran o disminuyeran su capacidad de solubilización a lo largo de las resiembras. Un total de 10 aislados (Pf_3, Pf_5, Pf_10, Pf_15, Pf_20, Pf_21, Pf_23, Pf_24, Pf_33 y Pf_35) mostraron tendencia a incrementar su capacidad de solubilización durante las resiembras. En contraste, 7 aislados (Pf_2,Pf_6, Pf_13, Pf_14, Pf_18, Pf_22, Pf_32) disminuyeron su capacidad de solubilización en la prueba de estabilidad. Por otra parte, 5 aislados se mantuvieron estables ( Pf 1, Pf 11, Pf 12, Pf 25, $\mathrm{Pf}$ 26). Finalmente, los restantes 13 aislados (Pf 4 , Pf_7, Pf_8, Pf 9, Pf_16, Pf_17, Pf_19, Pf_27, Pf_28, Pf_29, Pf_30, Pf_31, Pf_34) no mostraron ningún patrón definido en cuanto a su capacidad de solubilización. El detalle del comportamiento de la estabilidad de solubilización se muestra en la Figura 8. 


\section{Discusión}

Dentro de la actividad bacteriana en la rizósfera, se ha reportado la producción de ácidos orgánicos como un mecanismo que resulta en la solubilización de complejos insolubles de fósforo, volviéndolo disponible para el aprovechamiento de las plantas (Richardson et al., 2009). En las evaluaciones in vitro, se observó un cambio de coloración y formación de un halo alrededor de cada aislado, lo cual se relaciona a la producción de algún ácido orgánico debido al cambio del pH (Figura 5). Dicho ácido realizó la función de volver disponible el fósforo insoluble del $\mathrm{Ca}_{3}\left(\mathrm{PO}_{4}\right)_{2}$ utilizado en el medio de cultivo. Esto indica que los aislados evaluados tienen la capacidad de producir ácidos orgánicos como estrategia eficiente en la solubilización de fósforo y de esta forma hacerlo aprovechable para las plantas.

En los reportes de la actividad bacteriana relacionados a la solubilización de fósforo, se ha documentado la producción de ácidos de bajo peso molecular que inducen la acidificación del suelo o medio de cultivo (Khan et al., 2014; Richardson \& Simpson, 2011). La producción de ácidos orgánicos en Pseudomonas spp. ha sido identificada y se reporta una relación positiva entre la producción de ácido glucónico, ácido indolacético y ácido giberélico con la alta capacidad de solubilización de fósforo (Oteino et al., 2015; Suleman et al., 2018).

Al realizar la comparación de los valores de ISF obtenidos (Figura 6), se observa que la mayor parte de aislados produjeron valores en el rango de 2 a 4, los cuales son similares a los reportados en cultivos como café y hortalizas (Restrepo-Franco et al., 2015) maíz y frijol (Corrales-Ramírez et al., 2014), banano (Matos et al., 2017), uchuva (Becerra et al., 2012), papaya (Chan-Cupul et al., 2018), solanáceas (Gayosso-Barragán et al., 2017). Esto indica que los aislados bacterianos con capacidad solubilizadora pueden encontrarse en diversos agroecosistemas, y de implementarse un proceso de bioaumentación de estos microorganismos, se puede aumentar la disponibilidad del fósforo fijado en el suelo para que sea aprovechado por los cultivos y así disminuir las altas aplicaciones de fertilizantes fosfatados.

En cuanto a la estabilidad de solubilización (Figura 8), la cual se define como el patrón de solubilización en función del tiempo, el comportamiento variado obtenido en esta evaluación, también ha sido reportado previamente (Patiño-Torres \& Sánchez de Prager, 2012). La importancia de determinar la es- tabilidad de solubilización radica en que, al utilizar aislados bacterianos como biofertilizantes, se espera que estos mantengan su actividad de solubilización en el tiempo haciendo disponible el fósforo fijado en el suelo para su aprovechamiento por los cultivos que se establezcan en suelos biofertilizados. Si la actividad de solubilización se incrementa o se mantiene constante, se reduce la necesidad de aplicaciones de fósforo a través de fertilizantes de síntesis química, lo que disminuye la dependencia y problemas de contaminación ambiental asociados a estos. Por el contrario, aplicar biofertilizantes basados en aislados que disminuyen su estabilidad de solubilización, solo traerá consigo el rechazo de esta alternativa por parte de los productores, ya que la disponibilidad del fósforo irá disminuyendo en el tiempo, lo que obligaría a retomar las aplicaciones de fertilizantes de síntesis química. Ante lo expuesto, la determinación de la capacidad y estabilidad de solubilización son factores igualmente importantes que deben ser evaluados previo al desarrollo de formulaciones de biofertilizantes basados en aislados bacterianos.

En cuanto a los aislados que redujeron su estabilidad de solubilización, esto puede deberse a la ausencia de exudados producidos por las raíces, los cuales regulan la capacidad de colonización y multiplicación de los microorganismos, así como la producción de compuestos orgánicos implicados en la solubilización de fósforo (Hassan et al., 2019). Esta condición apunta a que algunos aislados son más sensibles a manifestar una reducción de su estabilidad de solubilización en ausencia de este tipo de compuestos orgánicos, por lo que, de ser seleccionados para el desarrollo de formulaciones de biofertilizantes, probablemente sean poco eficientes en la solubilización de fósforo.

Otro factor a considerar en la reducción de la estabilidad de solubilización es que, en condiciones naturales, las comunidades microbianas son altamente diversas y mantienen complejas interacciones, lo que conlleva a la regulación de los procesos metabólicos de las especies implicadas en la solubilización de fósforo (Goteti et al., 2014). Esto apunta a que, ante la ausencia de dichas interacciones, propias de un ambiente in vitro, algunos aislados bacterianos no activan las rutas metabólicas que conducen a la producción de los ácidos orgánicos implicados en el proceso de solubilización de fósforo.

La acumulación de metabolitos secundarios inhibitorios es otro factor que ha sido relacionado al descenso de la capacidad de solubilización en evaluaciones in vitro (Yadav et al., 2016). Sin embargo, este planteamiento podría ser refutable, ya que, en cada resiembra, los aislados fueron transferidos hacia me- 
Figura 5

Halos de solubilización de tres aislados nativos de P. fluorescens a los 15 días desde la siembra en medio NBRIP (a) Pf_33, (b) Pf_26 pertenecen al grupo A, (c) Pf_11 pertenece al grupo B del dendrograma NJ según su capacidad solubilizadora de $\mathrm{Ca}_{3}\left(\mathrm{PO}_{4}\right)_{2}$.
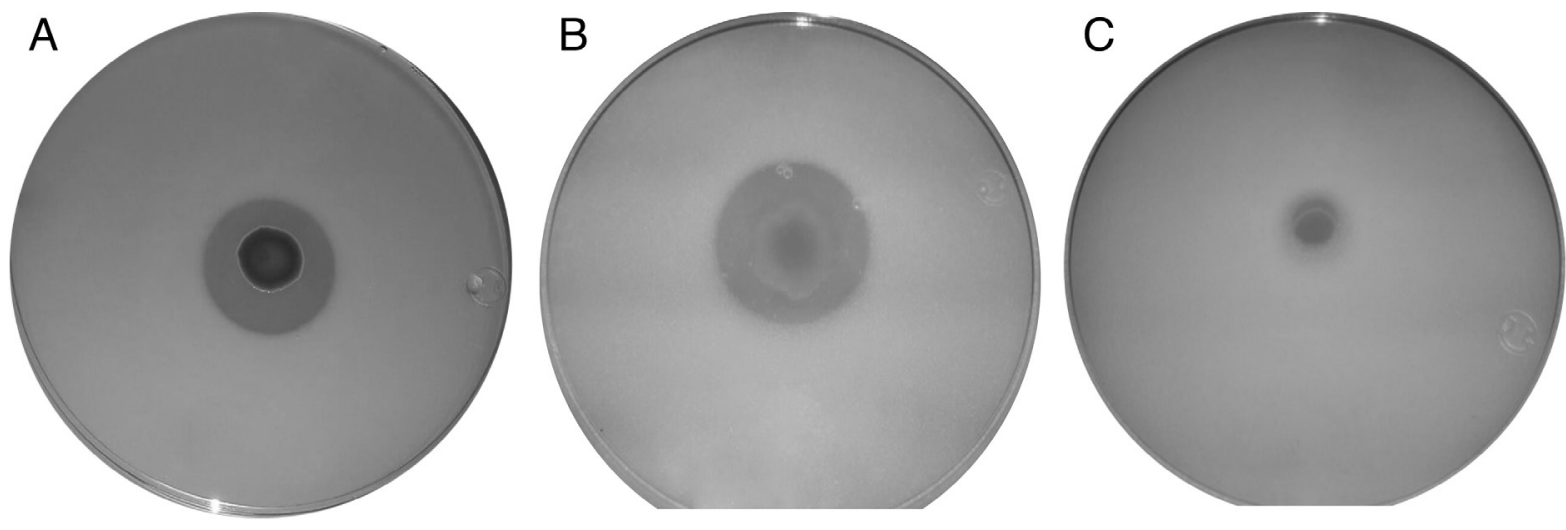

dios de cultivos nuevos sin presencia de metabolitos secundarios. Esto sugiere que el comportamiento de la estabilidad se explica de mejor forma por los factores de compuestos orgánicos producidos por las raíces y la interacción de los aislados bacterianos con el resto del consorcio microbiano, los cuales, en conjunto, estimulan la actividad de solubilización de fósforo de los aislados bacterianos.

A pesar de esto, existieron aislados como el Pf_33, Pf_18 y Pf_5, entre otros, que mantuvieron y/o aumentaron su capacidad de solubilización en cada resiembra. Esto muestra que la capacidad y estabilidad de solubilización de dichos aislados puede ser independiente de los factores mencionados, lo cual podría ser explicado por las condiciones del sitio de origen de estos. Es decir, si los aislados provienen de regiones con poca presencia de exudados radiculares y su vez, una baja abundancia de otros microorganismos, los aislados bacterianos estarían adaptados a realizar el proceso de solubilización de forma aislada. Esto explicaría el hecho de que su capacidad y estabilidad de solubilización no se vea afectada al ser evaluados in vitro, en donde los factores mencionados no están presentes. Esta condición de independencia a dichos factores, convierte a estos aislados en potenciales canditados para el desarrollo de biofertilizantes.

Por otra parte, a pesar de haber trabajado con la misma especie de bacteria, hubo una notable diferen- cia en la capacidad de solubilización entre los aislados provenientes de la región occidental y las zonas aledañas al altiplano central de Guatemala. Esta diferencia puede ser debida a que las comunidades microbianas presentan diferencia de su tasa metabólica en función de la temperatura. Al respecto, se ha reportado que el incremento de temperatura genera un aumento en la tasa metabólica de las comunidades microbianas microbianas (Dijkstra et al., 2011; Smith et al., 2019) por lo que, a pesar de que las condiciones de incubación oscilaron los $28^{\circ} \mathrm{C}$ para todos los aislados, es probable que la expresión metabólica se mantuviera en función a las condiciones de temperatura del sitio de colecta, existiendo aislados naturalmente más eficientes en la solubilización de P. Esto puede ser el resultado de un proceso evolutivo de adaptación a través del cambio de las frecuencias alélicas en los genes implicados en la solubilización del P.

Al analizar los valores de ISF, es claro que existe una relación entre la capacidad de solubilización y la temperatura, es decir, a mayor ISF mayor la temperatura de la región de donde provienen el aislado y viceversa. A pesar de esto, el hecho de evaluar a los aislados en condiciones diferentes a su lugar de procedencia, también pudo ser un factor que modificó su eficiencia de solubilización, ya que estos se encuentran adaptados a condiciones abióticas, como la temperatura, distintas a las encontradas en un ambiente in vitro. 
Figura 6

Diagrama de cajas de la capacidad de solubilización de fósforo $\mathrm{Ca}_{3}\left(\mathrm{PO}_{4}\right)_{2}$ bajo condiciones in vitro de cada uno de los aislados nativos de $\mathrm{P}$. fluorescens. El indice de solubilización representa la relación entre el diámetro del halo de solublización y diámetro de crecimiento de la colonia.

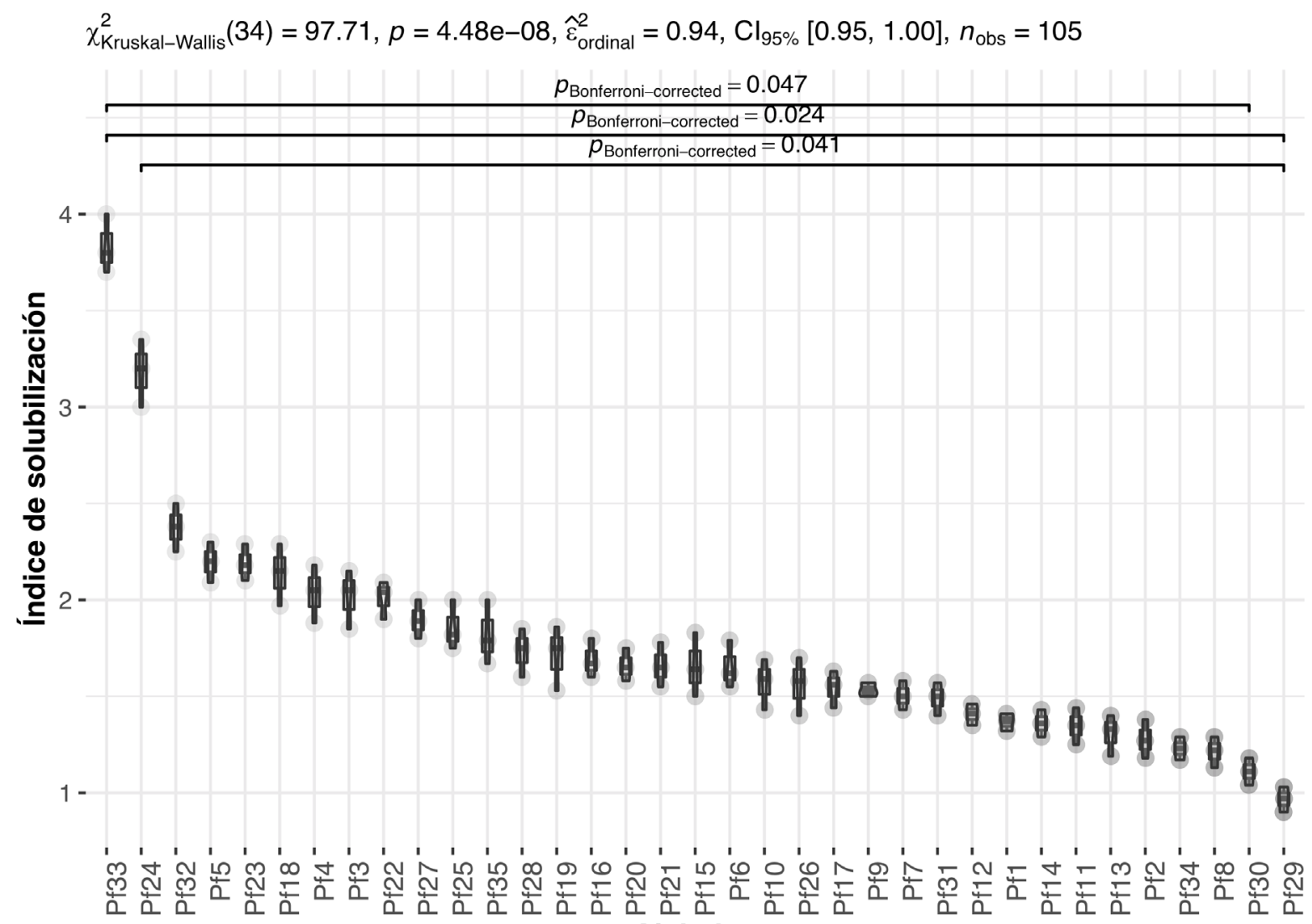

Aislados

Nota. Se muestran únicamente las comparaciones de medias significativas $p<.05$

Por esta situación, se sugiere evaluar el efecto de la temperatura, durante el proceso de incubación, sobre la efectividad de solubilización de los aislados, como sugiere el estudio de Porras y colaboradores (2002).

Esta variación, en la eficiencia de solubilización, también puede deberse a las complejas interacciones que se presenta a nivel de las comunidades microbianas en el suelo (Liu et al., 2019). Estas interacciones, propias de comunidades microbianas bajo un balance ecológico, pueden ser afectadas negativamente por factores como la fertilización química (Francioli et al., 2016; Wang et al., 2019) y la aplicación de pesticidas (Al-Ani et al., 2019; Arora \& Sahni, 2016) generándose la alteración de su diversidad y composición (Meena et al., 2020). Este escenario presenta una aceptable explicación al hecho que, los aislados más eficientes en la solubilización de fósforo provinieron de zonas boscosas naturales (Pf_33, Pf_24, Pf_32) o de sistemas agrícolas con cultivos de subsistencia (Pf_5, Pf_23) (Figura 2), y a pesar de que la evaluación in vitro se realizó con colonias bacterianas puras, es probable que los aislados de estas zonas hayan estado metabólicamente más activos por provenir de comunidades más diversas.

En ambos sistemas, la aplicación de moléculas químicas, con fines de fertilización o control de plagas y enfermedades, es inexistente o muy baja. Esto asegura que la diversidad de especies y dinámica microbiana no se encuentre alterada y, por lo tanto, la eficiencia de los microorganismos se potencialice al provenir de 
Figura 7

Diagrama de cajas de la capacidad de solubilización de fósforo $\mathrm{Ca}_{3}\left(\mathrm{PO}_{4}\right)_{2}$ bajo condiciones in vitro de los aislados nativos de $\mathrm{P}$. fluorescens a nivel de cada departamento de colecta. El índice de solubilización representa la relación entre el diámetro del halo de solublización y diámetro de crecimiento de la colonia.

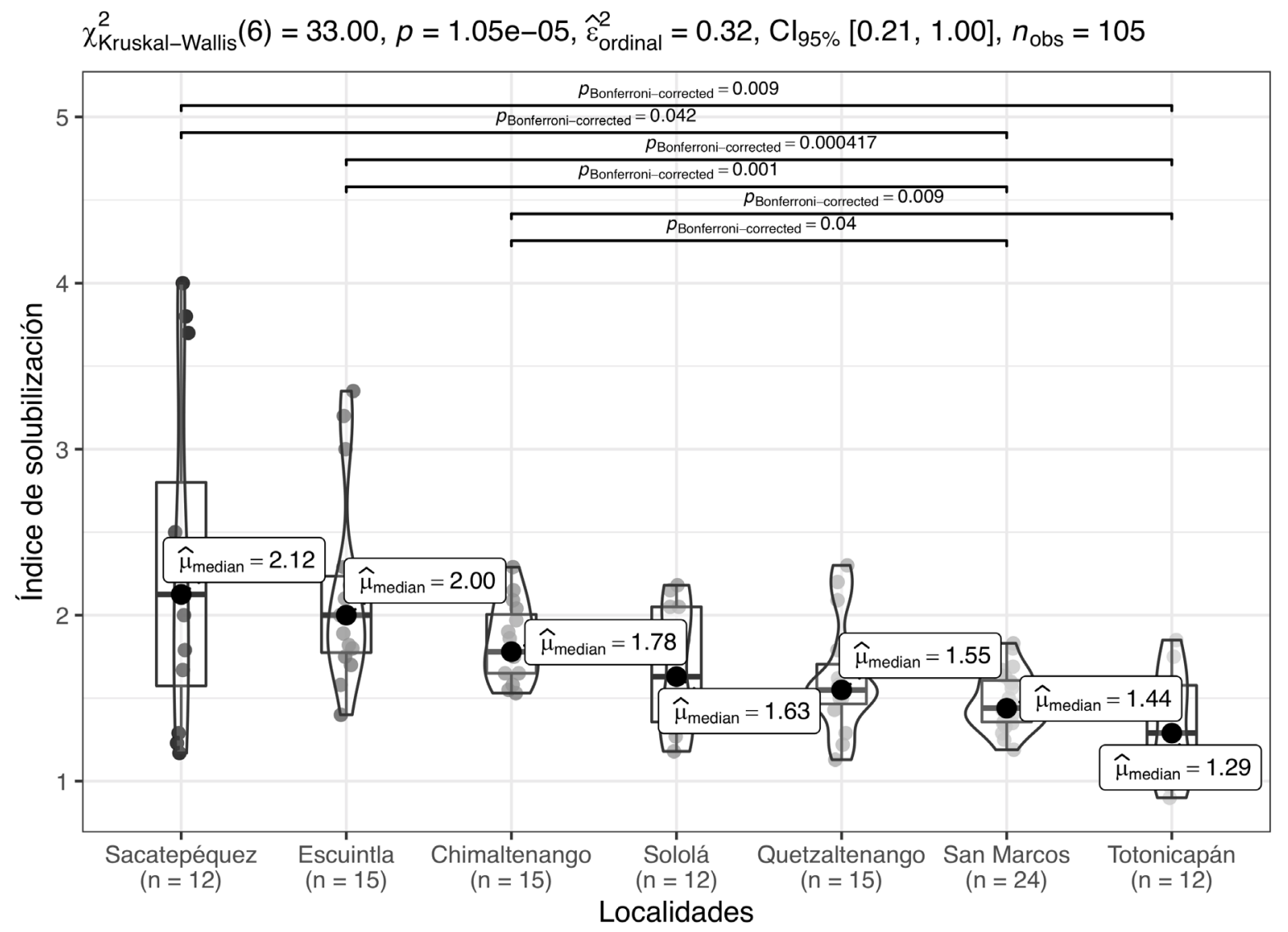

Nota. Se muestran únicamente las comparaciones de medias estadísticamente significativas $p<.05$.

suelos no contaminados (Delgado-Baquerizo et al., 2016). Esta potencialización puede deberse a que la disponibilidad del P depende mayormente de la actividad microbiana, por lo cual los aislados bacterianos deben ser altamente eficientes para poder suplir los requerimientos vegetales. Por el contrario, los aislados que presentaron los valores más bajos de ISF provinieron de sistemas de producción intensivos (Figura 2), en donde el balance de las comunidades microbianas ya ha sido alterado y los aislados bacterianos podrían ser menos eficientes en la solubilización debido a las aplicaciones externas de $\mathrm{P}$ para suplir los requerimientos nutricionales.

Una situación relevante del estudio es que los aislados que mostraron mayor capacidad de solubiliza- ción, también fueron organizados en un mismo grupo genético y viceversa. De tal manera, los grupos A y B del dendrograma estuvieron compuesto por los aislados con los ISF más altos y bajos, respectivamente. Este vínculo es sumamente importante, ya que debido al creciente interés en la formulación de biofertilizantes, ahora se conocen los sitios geográficos de donde se podría realizar el aislamiento de nuevos aislados bacterianos con altos valores de ISF, los cuales, al ser genéticamente similares, se esperaría que expresaran una alta actividad de solubilización de P. Este tipo de vínculo ha sido descrito anteriormente, donde se destaca la importancia de establecer el grado de cercanía genética entre los aislados, ya que este es un factor a considerar para establecer las zonas con presencia de 
Figura 8

Representación gráfica de la estabilidad en la solubilización de fósforo $\mathrm{Ca}_{3}\left(\mathrm{PO}_{4}\right)_{2}$ bajo condiciones in vitro de los aislados nativos de P. fluorescenes a lo largo de 5 resiembras. Los aislados están representados de acuerdo con su lugar de colecta para una mejor visualización. Las letras en cada gráfica indican el lugar de colecta (a) Escuintla, (b) Chimaltenango, (c) Sacatepéquez, (d) Sololá, (e) Totonicapán, (f) Quetzaltenango, (g) Totonicapán.
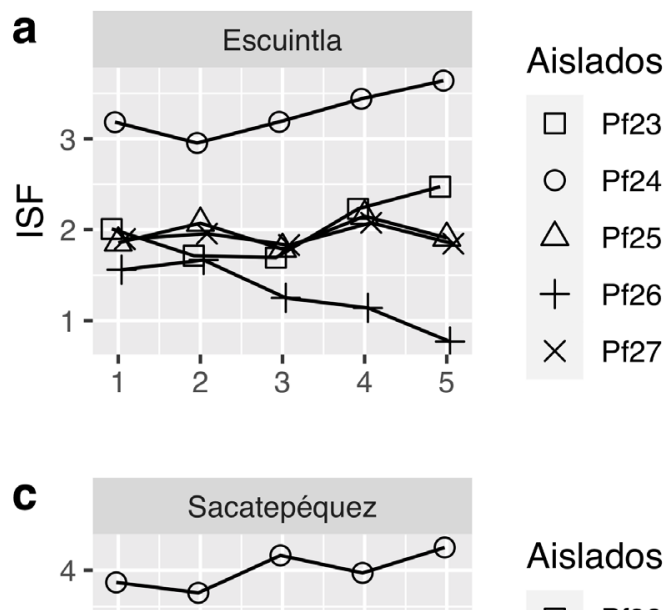

늠
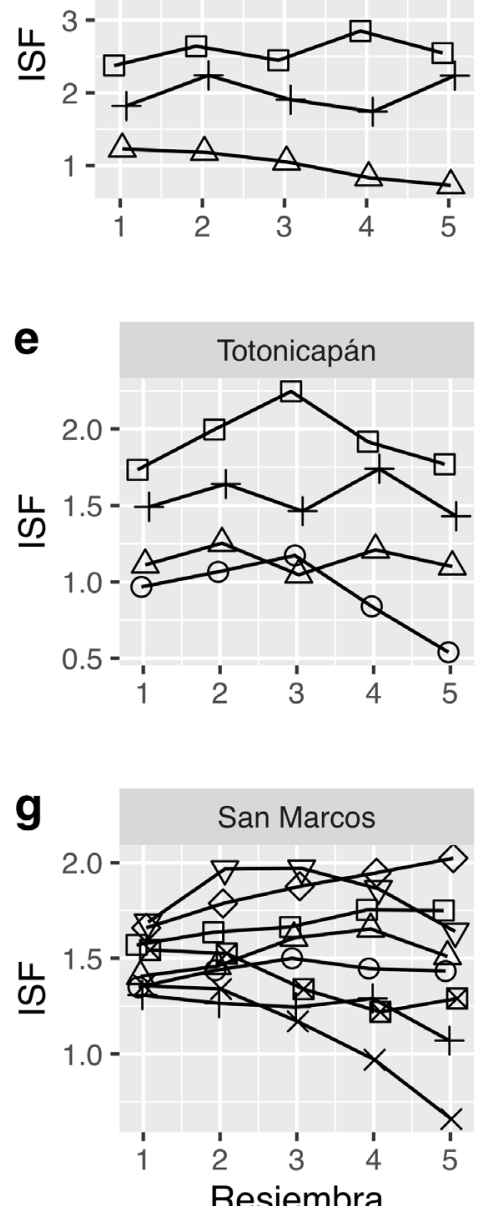

Resiembra
Aislados

$\square \quad \mathrm{Pf28}$

O Pf29

$\triangle \mathrm{Pf30}$

$+\quad$ Pf31

\section{Aislados}

$\square$ Pf10

O Pf11

$\triangle$ Pf12

$+\quad \mathrm{Pf13}$

$\times \quad \mathrm{Pf14}$

$\diamond \mathrm{Pf15}$

$\nabla \quad \mathrm{Pf16}$

$\begin{array}{ll}\triangle & \text { Pf17 }\end{array}$

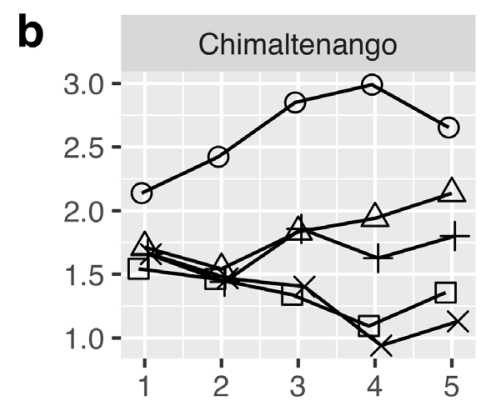

\begin{tabular}{cc}
\multicolumn{2}{r}{ Aislados } \\
$\square$ & Pf18 \\
O & Pf19 \\
$\triangle$ & Pf20 \\
+ & Pf21 \\
$\times$ & Pf22
\end{tabular}

\section{d}

Aislados

$\square \quad \mathrm{Pf32}$

○ Pf33

$\triangle$ Pf34

$+\quad \mathrm{Pf35}$

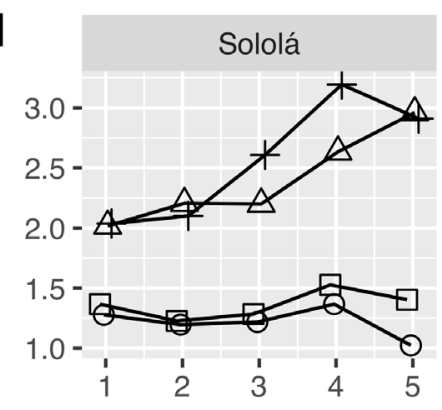

Aislados

$\square \quad \mathrm{Pf1}$

O Pf2

$\triangle \mathrm{Pf3}$

$+\quad \mathrm{Pf} 4$ 
aislados bacterianos con mayor capacidad de solubilización que pueden ser aprovechados para el desarrollo de biofertilizantes (Browne et al., 2009; Qessaoui et al., 2019).

Finalmente, los hallazgos de esta investigación demuestran que los aislados nativos de $P$. fluorescens tienen el potencial de ser una alternativa sostenible al ser utilizados como base para el desarrollo de futuros biofertilizantes. Esto representa un aporte en la búsqueda de soluciones a la problemática de la fijación del fósforo, de la cual resulta la actual dependencia a la fertilización química. Esta alternativa también resulta atractiva, ya que se ha demostrado, ampliamente, que el uso excesivo de fertilizantes de síntesis química tiene numerosos efectos negativos al ambiente, situación que se reduciría al utilizar estos aislados bacterianos. Ante lo promisorio de los hallazgos in vitro, se sugieren futuras investigaciones para evaluar la respuesta de los aislados del grupo genético A, pudiendo priorizarse en los aislados Pf_33, Pf_24, Pf_32, Pf_5, Pf_23 por su alta eficiencia y estabilidad de solubilización de $\mathrm{P}$, a diferentes condiciones de campo y diversidad de cultivos. Por consiguiente, se avanzará en el desarrollo de formulaciones de biofertilizantes eficientes que puedan ser distribuídos a los productores agrícolas nacionales.

\section{Agradecimientos}

A la Dirección General de Investigación (Digi) por financiar la presente investigación a través de la partida presupuestaria 4.8.63.4.45

\section{Contribución de los autores}

Coordinación, elaboración y revisión del Documento: JAR-C, JEB-S, AS, MK, BL, AS-P

Diseño de la recolección de datos o del trabajo en campo: JAR-C, JEB-S

Recolección o contribución de datos o realización del trabajo de campo: JAR-C, JEB-S

Limpieza, sistematización, análisis o visualización de datos: JAR-C, MK, BL

Participación en análisis de datos, estructura y en la escritura del documento: JAR-C, JEB-S, AS, EF, JZ, AS-P

\section{Materiales suplementarios}

No tiene materiales suplementarios

\section{Referencias}

Abdul-Wahab, A., Taj-Aldeen, S. J., Hagen, F., Diophode, S., Saadoon, A., Meis, J. F., \& Klaassen, C. H. (2014). Genotypic diversity of Pseudomonas aeruginosa in cystic fibrosis siblings in Qatar using AFLP fingerprinting. European Journal of Clinical Microbiology and Infectious Diseases, 33(2), 265-271. https://doi.org/10.1007/s10096-0131954-1

AL-Ani, M. A. M., Hmoshi, R. M., Kanaan, I. A., \& Thanoon, A. A. (2019). Effect of pesticides on soil microorganisms. Journal of Physics: Conference Series, 1294(7). Artículo 072007. https://doi.org/10.1088/1742-6596/1294/7/072007

AlKhader, A. M. (2015). The impact of phosphorus fertilizers on heavy metals content of soils and vegetables grown on selected farms in jordan. Agrotechnology, 5(1), Artículo 1000137. https://doi.org/10.4172/2168-9881.1000137

Alori, E. T., Glick, B. R., \& Babalola, O. O. (2017). Microbial phosphorus solubilization and its potential for use in sustainable agriculture. Frontiers in Microbiology, 8, 1-8. https://doi. org/10.3389/fmicb.2017.00971

Arora, S., \& Sahni, D. (2016). Pesticides effect on soil microbial ecology and enzyme activityAn overview. Journal of Applied and Natural Science, 8(2), 1126-1132. https://doi.org/10.31018/ jans.v8i2.929

Azziz, G., Bajsa, N., Haghjou, T., Taulé, C., Valverde, A., Igual, J. M., \& Arias, A. (2012). Abundance, diversity and prospecting of culturable phosphate solubilizing bacteria on soils under cropñpasture rotations in a no-tillage regime in Uruguay. Applied Soil Ecology, 61, 320-326. https://doi.org/ 10.1016/j.apsoil.2011.10.004

Batool, S., \& Iqbal, A. (2019). Phosphate solubilizing rhizobacteria as alternative of chemical fertilizer for growth and yield of Triticum aestivum (Var. Galaxy 2013). Saudi Journal of Biological Sciences, 26(7), 1400-1410. https://doi.org/ 10.1016/j.sjbs.2018.05.024

Becerra, J. M., Quintero, D., Martínez, M., \& Matiz, A. (2012). Caracterización de microorganismos solubilizadores de fosfato aislados de suelos destinados al cultivo de uchuva (Physalis 
peruviana L.). Revista Colombiana de Ciencias Hortícolas, 5(2), 186-194. https://doi.org/ 10.17584/rcch.2011v5i2.1265

Billah, M., Khan, M., Bano, A., Hassan, T. U., Munir, A., \& Gurmani, A. R. (2019). Phosphorus and phosphate solubilizing bacteria: Keys for sustainable agriculture. Geomicrobiology Journal, 36(10), 904-916. https://doi.org/10.108 0/01490451.2019.1654043

Borie, F., \& Rubio, R. (2003). Total and organic phosphorus in Chilean volcanic soils. Gayana Botanica, 60, 69-78. https://doi.org/10.4067/ S0717-66432003000100011.

Breitkreuz, C., Buscot, F., Tarkka, M., \& Reitz, T. (2020). Shifts between and among population of wheat rhizosphere Pseudomonas, Streptomyces and Phyllobacterium suggest consistent phosphate mobilization at different wheat growth stages under abiotic stress. Frontiers in Microbiology, 10, 3109. https://doi.org/10.3389/ fmicb.2019.03109

Browne, P., Rice, O., Miller, S. H., Burke, J., Dowling, D. N., Morrissey, J. P., \& OíGara, F. (2009). Superior inorganic phosphate solubilization is linked to phylogeny within the Pseudomonas fluorescens complex. Applied Soil Ecology, 43(1), 131-138. https://doi.org/10.1016/j.apsoil.2009.06.010

Callejas-Cañarte, G. V., Cisneros-Rojas, C. A., \& Caicedo-Bejarano, L. D. (2018). Capacidad solubilizadora de fosfato de aluminio por hongos rizosféricos aislados de un Andisol colombiano. Entramado, 14(2), 218-227. https://doi.org/ 10.18041/1900-3803/entramado.2.4745

Cerón, L., \& Aristizábal, F. (2012). Dinámica del ciclo del nitrógeno y fósforo en suelos. Revista Colombiana de Biotecnología, 14(1), 285-295.

Chan-Cupul, W., Juárez-González, M., Ruiz-Sánchez, E., Sánchez-Rangel, J., Molina-Ochoa, J., \& Galindo-Velasco, E. (2018). Solubilización de fuentes inorgánicas de fósforo por micromicetos aislados de la rizósfera de papaya var. Maradol (Carica papaya L.) y su susceptibilidad a herbicidas convencionales. Revista Internacional de Contaminacion Ambiental, 34(2), 281-284. https://doi.org/10.20937/rica.2018.34.02.09

Chawngthu, L., Hnamte, R., \& Lalfakzuala, R. (2020). Isolation and characterization of rhizospheric phosphate solubilizing bacteria from wetland paddy field of Mizoram, India. Geomicrobiology Journal, 37(4), 366-375. https://doi.org/10.1080/0 1490451.2019.1709108

Chowdhury, R. B., Moore, G. A., Weatherley, A. J., \& Arora, M. (2017). Key sustainability challenges for the global phosphorus resource, their implications for global food security, and options for mitigation. Journal of Cleaner Production, 140, 945-963. https://doi.org/10.1016/j. jclepro.2016.07.012

Cordell, D., Drangert, J. O., \& White, S. (2009). The story of phosphorus: Global food security and food for thought. Global Environmental Change, 19(2), 292-305. https://doi.org/10.1016/j. gloenvcha.2008.10.009

Cordell, D., Rosemarin, A., Schršder, J. J., \& Smit, A. L. (2011). Towards global phosphorus security: a systems framework for phosphorus recovery an reuse options. Chemosphere, 84(6), 747ñ758. https://doi.org/10.1016/j.chemosphere.2011.02.032

Corrales-Ramírez, L. C., Arévalo-Galvez, Z. Y., \& Moreno-Burbano, V. E. (2014). Solubilización de fosfatos: una función microbiana importante en el desarrollo vegetal. NOVA Publicación Científica en Ciencias Biomédicas, 12(21), 67-79. https://doi.org/ 10.22490/24629448.997

Dahlgren, R. A., Saigusa, M., \& Ugolini, F. (2004). The nature, properties and management of volcanic soils. Advanced Agronomy, 82, 113-181. https://doi.org/10.1016/S0065-2113(03)82003-5

de Mendiburu, F. \& Yassen, M. (2020). agricolae: Statistical procedures for agricultural research. R package version 1.4.0. https://myaseen208. github.io/agricolae/https://cran.r-project.org/ package $=$ agricolae.

Delfim, J., Schoebitz, M., Paulino, L., Hirzel, J., \& Zagal, E. (2018). Phosphorus availability in wheat, in volcanic soils inoculated with phosphatesolubilizing Bacillus thuringiensis. Sustainability, 10(1). https://doi.org/10.3390/su10010144

Delgado-Baquerizo, M., Grinyer, J., Reich, P. B., \& Singh, B. K. (2016). Relative importance of soil properties and microbial community for soil functionality: Insights from a microbial swap experiment. Functional Ecology, 30(11), 1862-1873. https://doi.org/10.1111/1365-2435.12674 
Dijkstra, P., Thomas, S. C., Heinrich, P. L., Koch, G. W., Schwartz, E., \& Hungate, B. A. (2011). Effect of temperature on metabolic activity of intact microbial communities: Evidence for altered metabolic pathway activity but not for increased maintenance respiration and reduced carbon use efficiency. Soil Biology and Biochemistry, 43(10), 2023-2031. https://doi.org/10.1016/j. soilbio.2011.05.018

Elekhtyar, N. (2016). Efficiency of Pseudomonas fluorescens as plant growth-promoting rhizobacteria (PGPR) for the enhancement of seedling vigor, nitrogen uptake, yield and its atrributes of rice (Oryza sativa L.). International Journal of Scientific Research in Agricultural Sciences, 2, 57-67.

Espinosa-Sánchez, J. A., \& Sanabria, Y. R. (2015). Procesos específicos de formación en Andisoles, Alfisoles y Ultisoles en Colombia. Escuela de Ingeniería de Antioquia, 12(3), E85-E97. https://doi.org/10.14508/reia.2015.11.E2.85-97

Francioli, D., Schulz, E., Lentendu, G., Wubet, T., Buscot, F., \& Reitz, T. (2016). Mineral vs. organic amendments: Microbial community structure, activity and abundance of agriculturally relevant microbes are driven by long-term fertilization strategies. Frontiers in Microbiology, 7, Artículo 1446. https://doi.org/10.3389/fmicb.2016.01446.

Gayosso-Barragán, O., Rodríguez-Herrera, S. A., López-Benítez, A., \& Luevanos-Escareño, M. P. (2017). Aislamiento e identificación de bacterias solubilizadoras de fosfatos y su potencial para disolver fosfato tricálcico. Revista de Investigación y Desarrollo, 3(7), 33-37.

Goteti, P. K., Desai, S., Emmanuel, L. D. A., Taduri, M., \& Sultana, U. (2014). Phosphate solubilization potential of fluorescent Pseudomonas spp. isolated from diverse agro-ecosystems of india. International Journal of Soil Science, 9(3), 101-110. https://doi.org/10.3923/ijss.2014.101.110

Hariprasad, P., \& Niranjana, S. (2009). Isolation and characterization of phosphate solubilizing rhizobacteria to improve plant health of tomato. Plant and Soil, 316, 13-24. https://doi.org/10.1007/ s11104-008-9754-6.

Hassan, M. K., McInroy, J. A., \& Kloepper, J. W. (2019). The interactions of rhizodeposits with plant growth-promoting rhizobacteria in the rhizosphere: A review. Agriculture, 9(7), Artículo 142. https://doi.org/10.3390/agriculture9070142

Hii, Y. S., Yen San, C., Lau, S. W., \& Danquah, M. K. (2020). Isolation and characterisation of phosphate solubilizing microorganisms from peat. Biocatalysis and Agricultural Biotechnology, 26(5), Artículo 101643. https:// doi.org/10.1016/j.bcab.2020.101643

Hou, E., Lu, X., Jiang, L., Wen, D., \& Luo, Y. (2019). Quantifying soil phosphorus dynamics: A data assimilation approach. Journal of Geophysical Research: Biogeosciences, 124(7), 2159-2173. https://doi.org/10.1029/2018JG004903

Islam, M. K., Sano, A., Majumder, M. S. I., Hossan, M. A., \& Sakagami, J. I. (2019). Isolation and molecular characterization of phosphate solubilizing filamentous fungi from subtropical soils in Okinawa. Applied Ecology and Environmental Research, 17(4), 9621-9650. https://doi.org/10.15666/aeer/1704

Johnsen, K., \& Nielsen, P. (1999). Diversity of Pseudomonas strains isolated with Kingís B and Gouldís S1 agar determined by repetitive extragenic palindromic-polymerase chain reaction, 16S rDNA sequencing and Fourier transform infrared spectroscopy characterisation. FEMS Microbiology Letters, 173(1), 155-162. https://doi.org/10.1016/S0378-1097(99)00065-8

Kalayu, G. (2019). Phosphate solubilizing microorganisms: Promising approach as biofertilizers. International Journal of Agronomy, Artículo 4917256. https://doi.org/10.1155/2019/ 4917256

Kamal, T. S., Huang, Y., Xu, S., Islam, I., \& Cui, S. (2019). Phosphorus demand for food security: A case study of a food-deficient country. Sustainability, 11(5), 1-18. https://doi.org/10.3390/ su11051345

Karam, D., Westra, P., Niessen, S. J., Ward, S. M., \& Figueiredo, J. E. F. (2006). Assessment of silver-stained AFLP markers for studying DNA polymorphism in proso millet (Panicum miliaceum L.). Revista Brasileira de Botanica, 29(4), 609-615. https://doi.org/10.1590/S010084042006000400011 
Khan, M. S., Zaidi, A., \& Ahmad, E. (2014). Mechanism of phosphate solubilization and physiological functions of phosphate-solubilizing microorganisms. En M. S. Khan, A. Zaidi \& J. Mussarrat (Eds.), Phosphate Solubilizing Microorganisms (pp. 34-35). Springer International Publishing. https://doi.org/10.1007/978-3=31908216-5_2

King, E., Ward, M., \& Raney, E. (1954). Two simple media for the demonstration of pyocyanin and luorescein. Journal of Laboratory Clinical Medicine, 44(2), 301-307.

Kruse, J., Abraham, M., Amelung, W., Baum, C., Bol, R., KŸhn, O., Lewandowski, H., Niederberger, J., Oelmann, Y., RŸger, C., Santner, J., Siebers, M., Siebers, N., Spohn, M., Vestergren, J., Vogts, A., \& Leinweber, P. (2015). Innovative methods in soil phosphorus research: A review. Journal of Plant Nutrition and Soil Science, 178(1), 43-88. https://doi.org/10.1002/jpln.201400327

Kuhad, R. C., SinghSurender, L., \& Singh, A. (2011). Phosphate solubilizing microorganisms. En A. Singh, N. Parmar \& C. Kuhad (Eds.), Bioaugmentation, biostimulation, biocontrol, soil biology (pp. 65-84). Springer.

Kumar, V., \& Narula, N. (1999). Solubilization of inorganic phosphates and growth emergence of wheat as affected by Azotobacter chroococcum mutants. Biology and Fertility of Soils, 28(3), 301-305. https://doi.org/10.1007/s003740050497

Kumar, P., Mahesh, M., Yoganada, V., \& Ammani, K. (2014). Molecular characterisation of Pseudomonas species isolated from diabetic patients with urinary tract infection (UTI) by AFLP. International Journal of Public Mental Health and Neurosciences, 1(1), 45-51.

Letunic, I \& Bork, P. (2019). Interactive Tree Of Life (iTOL) v4: recent updates and new developments. Nucleic acids research, 47(W1), W256-W259. https://doi.org/10.1093/nar/gkz239.

Liang, J. L., Liu, J., Jia, P., Yang, T. Tao, Zeng, Q. wei, Zhang, S. Chang, Liao, B., Shu, W. Sheng, \& Li, J. Tian. (2020). Novel phosphate-solubilizing bacteria enhance soil phosphorus cycling following ecological restoration of land degraded by mining. ISME Journal, 14, 1600-1613. https:// doi.org/10.1038/s41396-020-0632-4
Linu, M. S., Asok, A. K., Thampi, M., Sreekumar, J., \& Jisha, M. S. (2019). Plant growth promoting traits of indigenous phosphate solubilizing Pseudomonas aeruginosa isolates from chilli (Capsicumannuum L.) rhizosphere. Communications in Soil Science and Plant Analysis, 50(4), 444-457. https://doi.org/10.1080/ 00103624.2019.1566469

Liu, L., Li, A., Chen, J., Su, Y., Li, Y., \& Ma, S. (2018). Isolation of a phytase-producing bacterial strain from agricultural soil and its characterization and application as an effective eco-friendly phosphate solubilizing bioinoculant. Communications in Soil Science and Plant Analysis, 49(8), 984-994. https://doi.org/10.1080/00103624.2018.1448863

Liu, M., Sui, X., Hu, Y., \& Feng, F. (2019). Microbial community structure and the relationship with soil carbon and nitrogen in an original Korean pine forest of Changbai Mountain, China. $B M C$ Microbiology, 19(1), Artículo 218. https://doi. org/10.1186/s12866-019-1584-6

Matos, A., Gomes, I., Nietsche, S., Xavier, A., Gomes, W., Dos Santos, J., \& Pereira, M. (2017). Phosphate solubilization by endophytic bacteria isolated from banana trees. Anais Da Academia Brasileira de Ciências, 89(4), 2945-2955. https:// doi.org/10.1590/0001-3765201720160111

McPherson, M. R., Wang, P., Marsh, E. L., Mitchell, R. B., \& Schachtman, D. P. (2018). Isolation and analysis of microbial communities in soil, rhizosphere, and roots in perennial grass experiments. Journal of Visualized Experiments, 137, Artículo e57932. https://doi. org/10.3791/57932

Meena, R. S., Kumar, S., Datta, R., Lal, R., Vijayakumar, V., Brtnicky, M., Sharma, M. P.,Yadav, G. S., Jhariya, M. K., Jangir, C. K., Pathan, S. I., Dokulilova, T., Pecina, V., \& Marfo, T. D. (2020). Impact of agrochemicals on soil microbiota and management: A review. Land, 9(34), Artículo 34. https://doi.org/10.3390/ land9020034

Melenya, C., Logah, V., Aryee, D., Abubakari, A., Tuffour, H. O., \& Yeboah, I. B. (2015). Sorption of phosphorus in soils in the semi deciduous forest zone of Ghana. Applied Research Journal, 1(3), 169-175. 
Munir, I., Bano, A., \& Faisal, M. (2019). Impact of phosphate solubilizing bacteria on wheat (Triticum aestivum) in the presence of pesticides. Brazilian Journal of Biology, 79(1), 29-37. https://doi.org/10.1590/1519-6984.172213

Nautiyal, C. S. (1999). An effcient microbiological growth medium for screening phosphate solubilizing microorganisms. FEMS Microbiol Letters, 170, 265-270.

Obrist-Farner, J., Brenner, M., Curtis, J. H., Kenney, W. F., \& Salvinelli, C. (2019). Recent onset of eutrophication in Lake Izabal, the largest water body in Guatemala. Journal of Paleolimnology, 62(4), 359-372. https://doi.org/10.1007/s10933019-00091-3

Organización de las Naciones Unidas para la Agricultura y la Alimentación. (2019). World fertilizer trends and outlook to 2022. Rome.

Oteino, N., Lally, R. D., Kiwanuka, S., Lloyd, A., Ryan, D., Germaine, K. J., \& Dowling, D. N. (2015). Plant growth promotion induced by phosphate solubilizing endophytic Pseudomonas isolates. Frontiers in Microbiology, 6, Artículo 745. https://doi.org/10.3389/fmicb.2015.00745

Patil, I. (2021). Visualizations with statistical details: The 'ggstatsplotí approach. Journal of Open Source Software, 6(61), 3167. https://doi.org/ $10.21105 /$ joss. 03167

Patiño-Torres, C., \& Sánchez de Prager, M. (2012). Aislamiento e identificación de bacterias solubilizadoras de fosfatos, habitantes de la rizósfera de Chontaduro (B. gassipaes kunth). Biotecnología en el Sector Agropecuario y Agroindustrial, 10(2), 177-187.

Pérez-çlvarez, S., Coto-Arbelo, O., Echemendía-Pérez, M., \& çvila-Quezada, G. (2015). Pseudomonas fluorescens Migula, Àcontrol biológico o patógeno? Revista Protección Vegetal, 30(3), 225-234.

Pérez-Reynoso, J. R. (2008). Estudio de la concentración de cobre, zinc y manganeso en los suelos hortícolas del valle de San Pedro Almolonga, Quetzaltenango, sometidos a una agricultura intensiva [Tesis de licenciatura, Universidad de San Carlos de Guatemala]. http://biblioteca.usac. edu.gt/tesis/01/01_2441.pdf
Porras, M., Barrau, C., Santos, B., Arroyo, F. T., Blanco, C., \& Romero, F. (2002). Effects of temperature on in vitro response of Trichoderma strains against strawberry pathogen Rhizoctonia solani KŸhn. Plant Protection Science, 38(SI 2), 620-622. https://doi.org/10.17221/10572-pps

R Core Team. (2020). R: A language and environment for statistical computing. R Foundation for Statistical Computing, Vienna, Austria. https://www.R-project.org/.

Qessaoui, R., Bouharroud, R., Furze, J. N., El Aalaoui, M., Akroud, H., Amarraque, A., Vaerenbergh, J. Van, Tahzima, R., Mayad, E. H., \& Chebli, B. (2019). Applications of new rhizobacteria Pseudomonas isolates in agroecology via fundamental processes complementing plant growth. Scientific Reports, 9(1), 1-10. https://doi.org/10.1038/s41598-019-49216-8

Rahman, C. H., Miloud, B., Rachid, D., Ahcene, B., \& Hakim, H. (2017). Optimization of inorganic phosphate solubilization by Pseudomonas fluorescens and Bacillus sp. isolated from wheat rhizospheric soil. International Journal of Biosciences, 10(4), 142-150. https://doi.org/ 10.12692/ijb/10.4.142-150

Redel, Y., Rubio, R., Rouanet, J. L., \& Borie, F. (2007). Phosphorus biavailability affected by tillage and crop rotation on a Chilean volcanic derived ultisol. Geoderma, 139, 388-396. https://doi.org/ 10.1016/j.geoderma.2007.02.018

Rejmánková, E., Komárek, J., Dix, M., Komárková, J., \& Girón, N. (2011). Cyanobacterial blooms in Lake Atitlan, Guatemala. Limnologica, 41(4), 296302. https://doi.org/10.1016/j.limno.2010.12.003

Restrepo-Franco, G. M., Marulanda-Moreno, S., de la Fe-Pérez, Y., Díaz-de la Osa, A., Lucia-Baldani, V., \& Hernández-Rodríguez, A. (2015). Bacterias solubilizadoras de fosfato y sus potencialidades de uso en la promoción del crecimiento de cultivos de importancia económica. Revista CENIC Ciencias Biologicas, 46(1), 63-76.

Richardson, A. E., Barea, J. M., McNeill, A. M., \& Prigent-Combaret, C. (2009). Acquisition of phosphorus and nitrogen in the rhizosphere and plant growth promotion by microorganisms. Plant and Soil, 321(1-2), 305ñ339. https://doi.org/ 10.1007/s11104-009-9895-2 
Richardson, A. E., \& Simpson, R. J. (2011). Soil microorganisms mediating phosphorus availability. Plant Physiology, 156, 989-996.

Ryan, P. D., Hammer, ${ }^{-}$, \& Harper, D. A. (2001). Past: Paleontological Statistics Software Package for Education and Data Analysis. Palaeontologia Electronica, 4(1), 5-7. https://doi.org/10.1016/j. bcp.2008.05.025

Saitou, N., \& Nei, M. (1987). The neighbour-joining method: A new method for reconstructing phylogenetic trees. Molecular Biology and Evolution Biol Evo, 4(4), 406-425. https://doi.org/ 10.1093/oxfordjournals.molbev.a040454

Sarikhani, M. R., Aliasgharzad, N., \& Khoshru, B. (2020). P solubilizing potential of some plant growth promoting bacteria used as ingredient in phosphatic biofertilizers with emphasis on growth promotion of Zea mays L. Geomicrobiology Journal, 37(4), 327-335. https://doi.org/10.1080/ 01490451.2019 .1700323

Scarpellini, M., Franzetti, L., \& Galli, A. (2004). Development of PCR assay to identify Pseudomonas fluorescens and its biotype. FEMS Microbiology Ecology, 236(2), 257-260. https:// doi.org/10.1111/j.1574-6968.2004.tb0 965 5.x

Sharma, K. (2011). Inorganic phosphate solubilization by fungi isolated from agriculture soil. Journal of Phytology, 3(4), 11-12.

Shen, J., Yuan, L., Zhang, J., Li, H., Bai, Z., Chen, X., Zhang, W., \& Zhang, F. (2011). Phosphorus dynamics: From soil to plant. Plant Physiology, 156(3), 997-1005. https://doi.org/10.1104/ pp.111.175232

Situmorang, E. C., Prameswara, A., Sinthya, H. C., Toruan-Mathius, N., \& Liwang, T. (2015). Indigenous phosphate solubilizing bacteria from peat soil for an eco-friendly biofertilizer in oil palm plantation. KnE Energy, 1(1), 65-72. https://doi.org/10.18502/ken.vli1.324

Smith, T. P., Thomas, T. J. H., García-Carreras, B., Sal, S., Yvon-Durocher, G., Bell, T., \& Pawar, S. (2019). Community-level respiration of prokaryotic microbes may rise with global warming. Nature Communications, 10(1), Artículo 5124. https://doi.org/10.1038/s41467019-13109-1
Suleman, M., Yasmin, S., Rasul, M., Yahya, M., Manzoor, B., \& Mirza, M. (2018). Phosphate solubilizing bacteria with glucose dehydrogenase gene for phosphorus uptake and beneficial effects on wheat. PLoS ONE, 13(9), Artículo e0204408. https://doi.org/10.1371/journal.pone.0204408

Tak, H. I., Ahmad, F., Babalola, O. O., \& Inam, A. (2012). Growth, photosynthesis and yield of chickpea as influenced by urban wastewater and different levels of phosphorus. International Journal of Plant Research, 2, 6-13. https://doi.org/10.5923/j.plant.20120202.02

Velásquez, G., Calabi-Floody, M., Poblete-Grant, P., Rumpel, C., Demanet, R., Condron, L., \& Mora, M. L. (2016). Fertilizer effects on phosphorus fractions and organic matter in Andisols. Journal of Soil Science and Plant Nutrition, 16(2), 294-309. https://doi.org/10.4067/S071895162016005000024

Vos, P., Hogers, R., Bleeker, M., Reijans, M., van de Lee, T., Hornes, M., Friters, A., Pot, J., Paleman, J., Kuiper. (1995). AFLP: A new technique for DNA fingerprinting. Nucleic Acids Research, 23(21), 4407-4414. https://doi.org/10.1093/ nar/23.21.4407

Wang, Z., Liu, Y., Zhao, L., Zhang, W., \& Liu, L. (2019). Change of soil microbial community under long-term fertilization in a reclaimed sandy agricultural ecosystem. PeerJ, 7, Artículo e6497. https://doi.org/10.7717/peerj.6497

Yadav, A., Yadav, K., \& Vashistha, A. (2016). Phosphate solubilizing activity of Pseudomonas fluorescens PSM1 isolated from wheat rhizosphere. Journal of Applied and Natural Science, 8(1), 93-96. https://doi.org/10.31018/jans.v8i1.754 